\title{
¿Inhomogeneity of the Surface Air Temperature Record from Halley, Antarctica
}

\author{
John C. King, ${ }^{a}$ John Turner, ${ }^{a}$ Steve Colwell, ${ }^{a}$ Hua Lu, ${ }^{\text {a }}$ ANDrew OrR,,${ }^{a}$ Tony Phillips, ${ }^{a}$ \\ J. SCOTt Hosking, ${ }^{a}$ AND GARETH J. MARSHALL ${ }^{\mathrm{a}}$ \\ ${ }^{a}$ British Antarctic Survey, Cambridge, United Kingdom
}

(Manuscript received 25 September 2020, in final form 10 March 2021)

\begin{abstract}
Commencing in 1956, observations made at Halley Research Station in Antarctica provide one of the longest continuous series of near-surface temperature observations from the Antarctic continent. Since few other records of comparable length are available, the Halley record has been used extensively in studies of long-term Antarctic climate variability and change. The record does not, however, come from a single location but is a composite of observations from a sequence of seven stations, all situated on the Brunt Ice Shelf, that range from around 10 to $50 \mathrm{~km}$ in distance from the coast. Until now, it has generally been assumed that temperature data from all of these stations could be combined into a single composite record with no adjustment. Here, we examine this assumption of homogeneity. Application of a statistical changepoint algorithm to the composite record detects a sudden cooling associated with the move from Halley IV to Halley V station in 1992. We show that this temperature step is consistent with local temperature gradients measured by a network of automatic weather stations and with those simulated by a high-resolution atmospheric model. These temperature gradients are strongest in the coastal region and result from the onshore advection of maritime air. The detected inhomogeneity could account for the weak cooling trend seen in the uncorrected composite record. In future, studies that make use of the Halley record will need to account for its inhomogeneity.
\end{abstract}

KEYWORDS: Atmosphere; Antarctica; Ice shelves; Temperature; Climate records; Changepoint analysis

\section{Introduction}

On 6 January 1956, the Royal Society established a station on the Brunt Ice Shelf, Coats Land, Antarctica (see Fig. 1 for location) as part of the United Kingdom's contribution to the International Geophysical Year (IGY) of 1957-58. The station, originally named "Halley Bay" but renamed "Halley" in 1977, was operated as an atmospheric and geophysical observatory through the IGY. In 1959, the Falkland Islands Dependencies Survey (FIDS), which later became the British Antarctic Survey (BAS), assumed responsibility for the station and its observing programs. Apart from a few short interruptions, surface meteorological observations have been made continuously at the station since shortly after its establishment in 1956, forming one of the longest continuous climate records from the Antarctic continent.

Halley is a key station in the Antarctic climate monitoring network. The nearest stations with comparable records are Belgrano II station, $340 \mathrm{~km}$ southwest of Halley (record starting in April 1980, but data are incomplete in some years) and Neumayer station, $775 \mathrm{~km}$ northeast of Halley (record starting in February 1981), while Novolazarevskaya, $1280 \mathrm{~km}$ eastnortheast of Halley (record starting in 1961), is the only nearby station with a record of comparable length. The regional climate observing network is thus extremely sparse, so, in contrast to other regions of the globe, our knowledge of regional climate variability and change relies heavily on single station records. Given the lack of other long series of climate observation from

¿ Denotes content that is immediately available upon publication as open access.

Corresponding author: John C. King, jcki@bas.ac.uk the region, the Halley record has been used extensively in studies of Antarctic multidecadal climate variability and change (e.g., Raper et al. 1984; Chapman and Walsh 2007; Turner et al. 2005). Because this record carries a high weight in such regional climate studies, quantifying its accuracy is of crucial importance.

Because Halley is situated on a floating ice shelf, it does not occupy a fixed geographical location but moves with the flow of the ice shelf between 360 and $850 \mathrm{~m}$ each year in an approximately westward direction. In addition to this gradual movement, the station has been rebuilt and relocated on several occasions. Halley I-IV were subsurface structures that became increasingly buried as a result of 1-2 $\mathrm{m}$ of annual snow accumulation on the ice shelf, necessitating periodic rebuilding. Additionally, when a station approaches the calving front of the ice shelf it has to be relocated farther upstream to avoid the possibility of it breaking off on an iceberg. Since the original station was established, the station has been moved to seven different locations on the ice shelf, ranging from less than $10 \mathrm{~km}$ to around $50 \mathrm{~km}$ in distance from the coast. As the surface of the ice shelf is very flat and uniform, and since short periods of overlapping measurements carried out at the times of some station moves did not reveal any significant temperature differences, it has generally been assumed that the individual temperature records from each of these stations can be combined into a long composite record without adjustment. However, the homogeneity of the composite record has recently been questioned. In their study of long-term temperature records from the Antarctic, Turner et al. (2020) noted that the composite Halley record contained at least one sudden jump that coincided with a station move. Because of this possible

This article is licensed under a Creative Commons Attribution 4.0 license (http://creativecommons.org/ licenses/by/4.0/).

DOI: 10.1175/JCLI-D-20-0748.1 


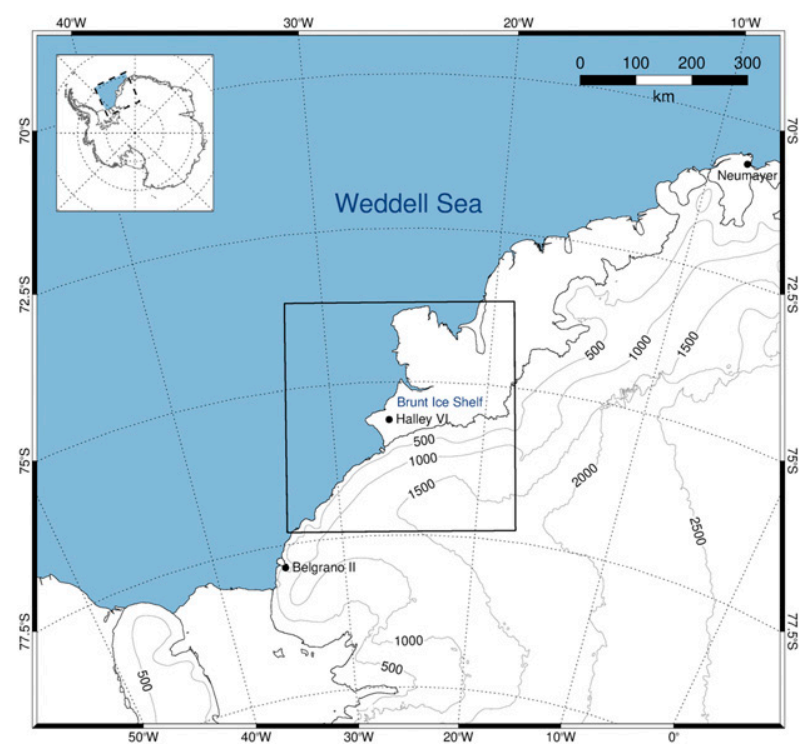

FIG. 1. The location of Halley station in 2016 on the Brunt Ice Shelf. The outlined box indicates the extent of the inner $(1.5 \mathrm{~km})$ domain of the regional atmospheric model described in section $3 \mathrm{~d}$. Also shown are the locations of nearest-neighbor stations Belgrano II and Neumayer. The map was produced using data from the SCAR Antarctic Digital Database (https://www.add.scar.org/).

inhomogeneity, they chose not to include the composite Halley record in their study.

The Weddell Sea adjoining the Brunt Ice Shelf is largely covered in sea ice during winter but becomes ice-free in summer. Even during winter, the sea ice is typically no more than $0.5-1 \mathrm{~m}$ thick, and areas of open water (coastal polynyas) persist along the coast (Markus et al. 1998). As a result, surface temperatures over the sea ice and the open ocean remain significantly higher than those over the ice shelf throughout the year. It is thus likely that strong spatial temperature gradients exist in the near-coastal region, particularly under conditions when (relatively warm) air is advected from the ocean over the (relatively cold) ice shelf. However, to date, there have been no detailed studies of the spatial variation of temperature in this region. As the location of the station relative to the coast has changed over the years, the presence of strong spatial temperature gradients could have introduced spurious temporal variations into the composite temperature record from the Halley stations, which consequently may not accurately reflect the true long-term variability of temperature in this region.

In this paper we examine the effects that the relocations and intervening gradual movement of Halley have had on the composite temperature record. In particular, we attempt to determine whether the composite record from the various Halley stations can be regarded as homogeneous and hence address this question: Does the Halley composite temperature record exhibit a spurious trend as a result of the movement of the station relative to the coastline? In recent years, considerable progress has been made in developing techniques for automatically detecting and correcting inhomogeneities in station climate records used to produce global or regional gridded datasets (e.g., Menne and Williams 2009; Venema et al. 2012). These techniques generally rely on the existence of a relatively dense observing network so that records from one station can be compared with those from near neighbors across a region that can be regarded as climatologically homogeneous. Because the climate observing network across most of the Antarctic is too sparse to permit the application of such techniques, our focus in this paper is on the analysis of a single composite record for which we have reliable metadata and some understanding of the processes that may be contributing to inhomogeneity.

Our paper is organized as follows: in section 2, we provide further detail on the geographical setting of Halley and on regional climatology. In section 3 we describe the sources of observational and model data that we use. In section 4 we present the results of a statistical analysis of the homogeneity of the Halley composite record. We then use observations and the results of a high-resolution simulation with a regional atmospheric model to examine spatial temperature gradients across the Brunt Ice Shelf, and we subsequently investigate how such gradients may have affected the homogeneity of the composite Halley temperature record. In section 5, we present our conclusions and make recommendations on the future use of the composite Halley record in climatological studies.

\section{The physical and climatological setting}

Each of the Halley stations has been located on the Brunt Ice Shelf, a medium-sized floating ice shelf on the southeastern shores of the Weddell Sea, adjoining the Coats Land region of the continent. The initial locations and periods of operation of all seven Halley stations are given in Table 1 . The ice shelf has a mean surface elevation of around $30 \mathrm{~m}$ above mean sea level and is bounded by the Weddell Sea to the north and west, to the east by the Stancomb-Wills Glacier Tongue and to the south by the Antarctic continent. The surface of the ice shelf is mostly very uniform and level (slopes are generally less than 1:1000), although a region of disturbed ice with large crevasses exists in the region where the floating ice shelf becomes grounded and meets the continent. Inland of this region, the continental ice rises steeply to the Coats Land plateau, at an elevation of around $1600 \mathrm{~m}$.

In common with other ice shelves, the coastline of the Brunt Ice Shelf is not fixed but evolves over time in response to the flow of ice through the ice shelf and the episodic calving of icebergs from the coast. Typically, the ice front advances steadily for several decades, after which the calving of a large iceberg causes a sudden retreat. Since Halley was established in 1956 ground surveys and satellite imagery have detected only a single large calving event, which occurred around $60 \mathrm{~km}$ east of Halley in December 1971. There have been no further major iceberg calving events and the western coast of the ice shelf advanced by approximately $25 \mathrm{~km}$ between 1958 and 2011 (Anderson et al. 2014). Figure 2 shows positions of each of the Halley stations at 2-yearly intervals together with ice shelf coastlines at times representative of the beginning and end of operation of each station. It is clear that the distance of the station from the western ice front has changed significantly over the period that the station has been established, ranging 
TABLE 1. Periods of operation and locations for each of the Halley stations. Station moves always took place in January or February, with the latest move (from Halley V to Halley VI) occurring on 14 Feb. The start year given is that in which observations from the new station commenced. The end year is the last year for which a complete year of observations was available from the old station. The final column gives the approximate distance of the station from the coast along a bearing of $250^{\circ}$, which is the modal wind direction for winds in the westerly (onshore) sector.

\begin{tabular}{lccccr}
\hline \hline Station & Start year & End year & Start position & End position & Distance from coast $(\mathrm{km})$ \\
\hline Halley I & 1957 & 1967 & $75.51^{\circ} \mathrm{S}, 26.60^{\circ} \mathrm{W}$ & $75.52^{\circ} \mathrm{S}, 26.74^{\circ} \mathrm{W}$ & 8 \\
Halley II & 1968 & 1973 & $75.51^{\circ} \mathrm{S}, 26.65^{\circ} \mathrm{W}$ & $75.51^{\circ} \mathrm{S}, 26.72^{\circ} \mathrm{W}$ & 9 \\
Halley III & 1974 & 1983 & $75.51^{\circ} \mathrm{S}, 26.74^{\circ} \mathrm{W}$ & $75.52^{\circ} \mathrm{S}, 26.98^{\circ} \mathrm{W}$ & 7 \\
Halley IV & 1984 & 1991 & $75.60^{\circ} \mathrm{S}, 26.60^{\circ} \mathrm{W}$ & $75.61^{\circ} \mathrm{S}, 26.81^{\circ} \mathrm{W}$ & 14 \\
Halley V & 1992 & 2011 & $75.58^{\circ} \mathrm{S}, 26.33^{\circ} \mathrm{W}$ & $75.58^{\circ} \mathrm{S}, 26.74^{\circ} \mathrm{W}$ & 25 \\
Halley VI & 2012 & 2017 & $75.62^{\circ} \mathrm{S}, 26.21^{\circ} \mathrm{W}$ & $75.61^{\circ} \mathrm{S}, 26.29^{\circ} \mathrm{W}$ & 35 \\
Halley VIa & 2018 & - & $75.57^{\circ} \mathrm{S}, 25.47^{\circ} \mathrm{W}$ & - & 50 \\
\hline
\end{tabular}

from less than $10 \mathrm{~km}$ for Halley I-III to around $50 \mathrm{~km}$ for Halley VIa, as successive stations have been built at increasing distances from the coast.

The Weddell Sea adjoining the ice shelf remains frozen for much of the year, but a broad lead of open water extends along the ice shelf coast during austral summer (Fig. 3a). Even during austral winter, when the majority of the Weddell Sea is icecovered (Fig. 3b), the prevailing easterly winds and westwardflowing Antarctic Coastal Current act to maintain areas of open water (coastal polynyas; Fig. 3c) off the western coast of the ice shelf (Markus et al. 1998). As surface temperatures in these polynyas remain close to the freezing point of seawater $\left(-1.8^{\circ} \mathrm{C}\right)$ while mean winter air temperatures over the surrounding Weddell Sea are typically around $-20^{\circ} \mathrm{C}$, these features are regions of intense air-sea heat fluxes (Fiedler et al.
2010; Renfrew et al. 2002; Markus et al. 1998) that can significantly warm the air over the polynya and, with an onshore wind, cause warming over the coastal region of the adjoining ice shelf.

The climate of Halley is characteristic of the coast of East Antarctica (König-Langlo et al. 1998). Monthly mean temperatures range from around $-5^{\circ} \mathrm{C}$ in January to around $-29^{\circ} \mathrm{C}$ in July. The standard deviation of the monthly mean temperature is largest in winter, varying from $1^{\circ} \mathrm{C}$ in December to $3.7^{\circ} \mathrm{C}$ in June. High temperatures in the winter months are associated with low pressure in the Weddell Sea and correspondingly low sea ice concentration off the coast from Halley. Wind speeds are moderate by Antarctic standards, averaging around $7 \mathrm{~m} \mathrm{~s}^{-1}$ over the year. The wind direction distribution is bimodal (Fig. 4), with $58 \%$ of winds falling in the sector $50^{\circ}-120^{\circ}$, reflecting the dominance of the Antarctic coastal
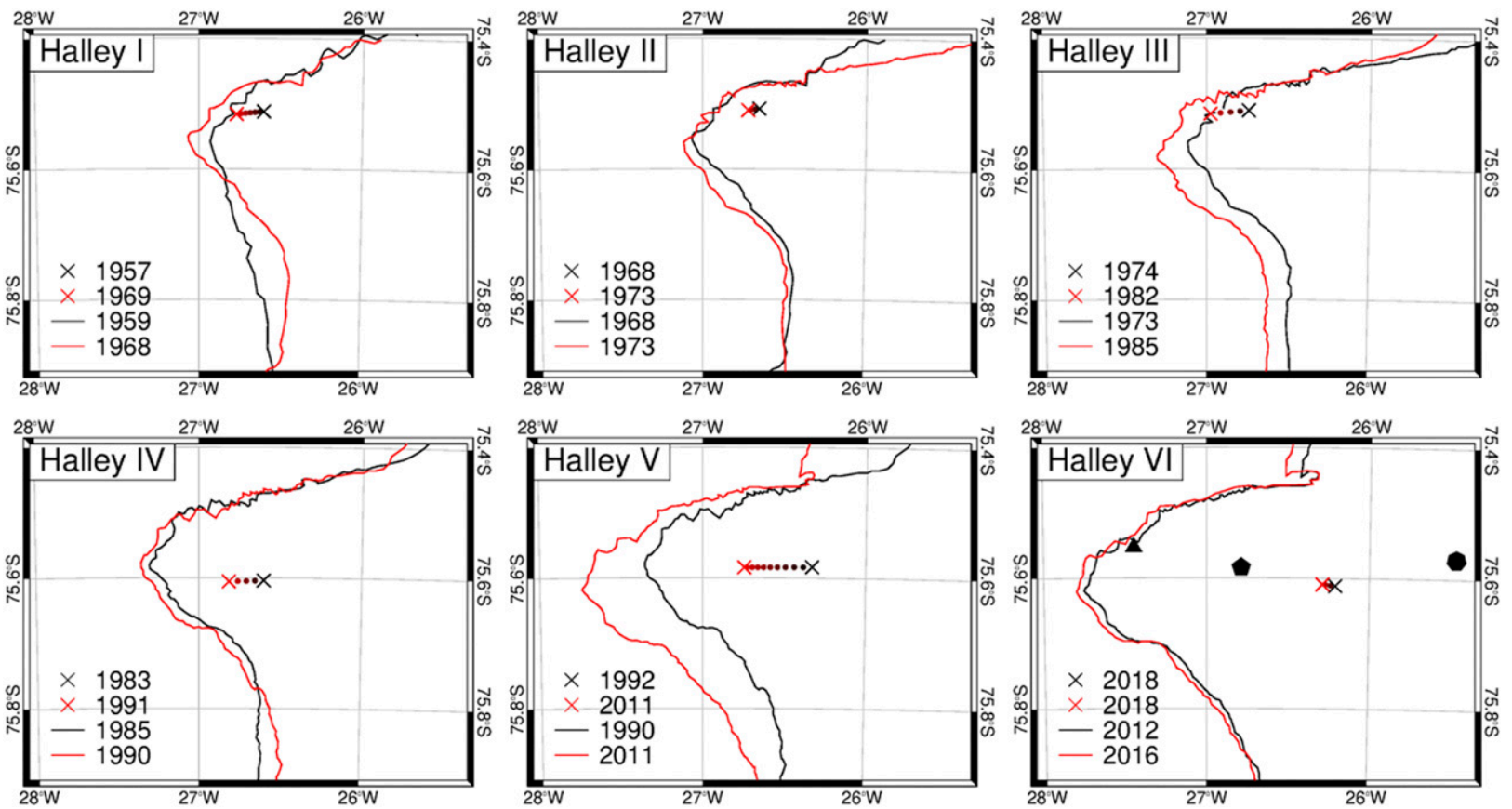

FIG. 2. The initial (black crosses) and final (red crosses) locations of each of the Halley stations. Dots indicate the station locations at 2yr intervals. The solid black and red lines indicate the locations of the ice front at times close to the start and end of operation of each station (years indicated in the legend for each panel). Also shown on the Halley VI panel are the locations of automatic weather stations A (filled triangle) and B (filled pentagon; see section 3b) and the 2016 location of Halley VIa (filled heptagon). 

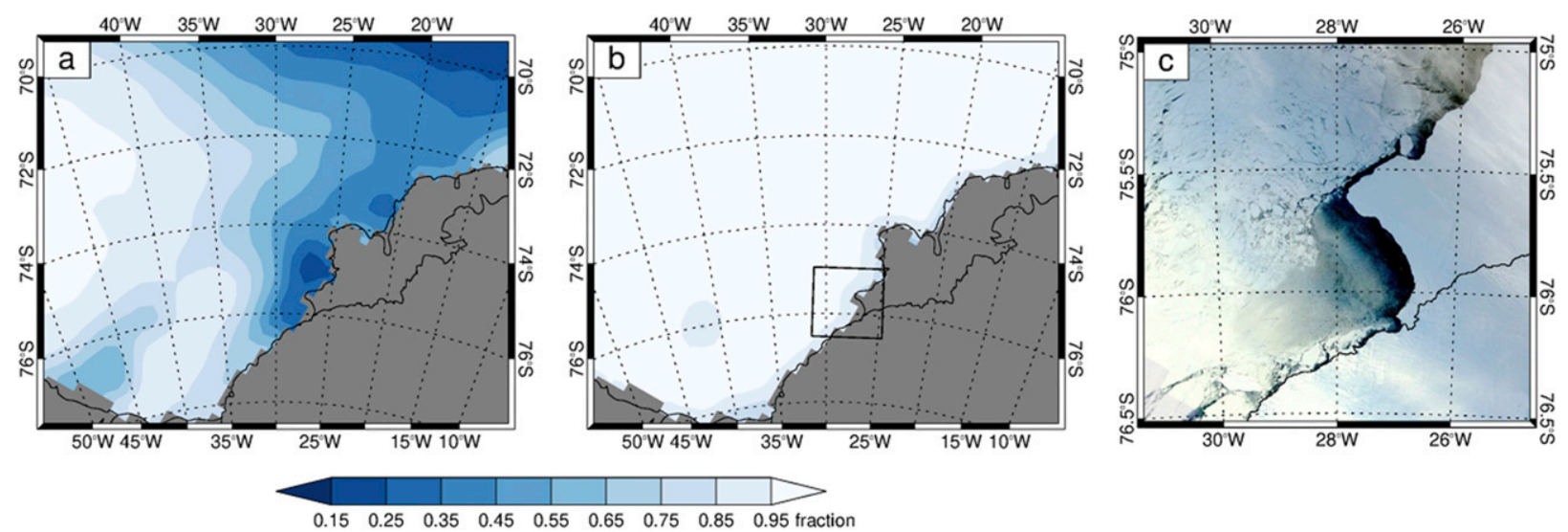

FIG. 3. Sea ice concentration in the southeastern Weddell Sea and in the vicinity of the Brunt Ice Shelf, showing mean sea ice concentration from 2000 to 2018 for (a) January and (b) July, derived from satellite passive microwave measurements using the NASA bootstrap algorithm. Also shown is a (c) Terra/MODIS visible satellite image from 1 Apr 2019 (source: NASA Worldview; https://worldview.earthdata.nasa.gov) covering the area shown by the outlined box in (b). Note the large coastal polynya off the west coast of the Brunt Ice Shelf.

easterlies, and a secondary maximum (23\%) occurring in the westerly sector $\left(230^{\circ}-300^{\circ}\right)$. Strong downslope-directed katabatic winds frequently occur over the steep continental slopes that adjoin the ice shelf, but these do not penetrate onto the ice shelf itself (Renfrew and Anderson 2002). All sites occupied by Halley station have an upwind fetch of at least $50 \mathrm{~km}$ across a very uniform ice shelf surface when the wind is in the easterly sector. By contrast, winds from the westerly sector, which originate over sea ice and open water in the Weddell Sea, have a relatively short fetch over the ice shelf before reaching Halley. As can be seen from Fig. 2, the length of this fetch varies considerably depending on the location of Halley relative to the west coast of the ice shelf.

At Halley, winds from the westerly sector are associated with freezing fogs, indicative of their maritime origin (Anderson 1993). Air masses from this sector are warmed at low levels by the sensible heat flux that results from their passage over relatively warm sea ice and coastal polynyas, leading to the development of a shallow convective internal boundary layer (Culf 1989). Once a column of air crosses the coast onto the relatively cold ice shelf, the sensible heat flux reverses sign, resulting in the development of a stable internal boundary layer and associated surface inversion that will increase in strength with increasing fetch inland from the coast. In contrast to winds from the easterly sector, which have a long and uniform fetch across the ice shelf, winds from the westerly sector are thus likely to be associated with significant horizontal temperature gradients. In section 4 below we use observations and model data to test the hypothesis that mean temperature gradients across the ice shelf are largely controlled by the advection of air that has been warmed at low levels during periods of westerly sector winds.

\section{Data and methods}

\section{a. Climate data}

Meteorological observations for Halley and neighboring Antarctic stations (Belgrano II and Neumayer) have been obtained from the database of surface meteorological and climatological observations assembled by the Reference Antarctic Data for Environmental Research (READER) project of the Scientific Committee on Antarctic Research (SCAR) (Turner et al. 2004). Quality-controlled monthly mean data for Halley and other Antarctic stations are available from the READER website (https:/www.bas.ac.uk/met/READER/). The synoptic observations from which the monthly means were derived are also available online (ftp://ftp.bas.ac.uk/src/ANTARCTIC_ METEOROLOGICAL_DATA/SURFACE/).

From the establishment of Halley in 1956, until 1986, air temperature measurements at a nominal height of $1.5 \mathrm{~m}$ were made manually at 3-hourly intervals using mercury-thallium thermometers in a standard Stevenson screen. From 1987 onward, measurements have been made automatically, initially using temperature probes in a Stevenson screen but, from 1999

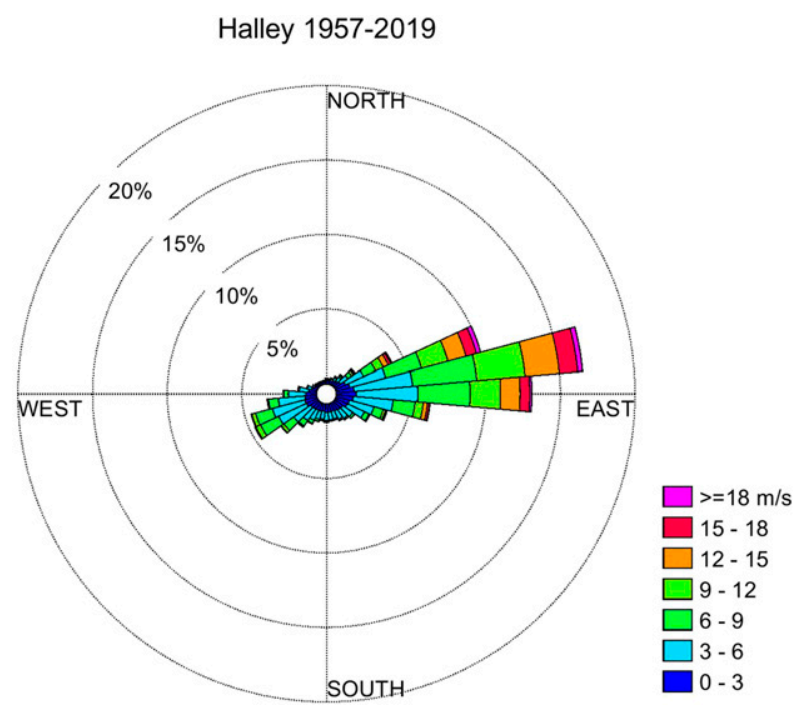

FIG. 4. A 10-m wind rose for Halley constructed from synoptic observations made from 1957 to 2019. 
onward, probes were housed in miniature aspirated radiation shields. Whenever the instrumentation was changed the old and new systems were run in parallel for at least one year and we are confident that instrumentation changes have not introduced any significant inhomogeneity into the composite record. In this paper we use Halley data starting in 1957, the first full year for which observations are available.

At Belgrano II, temperature readings were nominally taken at 6-hourly intervals. Readings at 0000, 1200, and 1800 UTC are available for most of the record, but the 0600 UTC readings are frequently missing. To construct homogeneous series of monthly and annual mean temperatures for Belgrano II we have calculated means from the 0000, 1200, and 1800 UTC observations only. Comparison of these means with those calculated from all four daily observations for periods when the 0600 UTC observation was available shows that, although the time series based on three observations per day has a slightly higher mean, it closely reproduces the interannual variability in the more complete record.

\section{b. Automatic weather station data}

Unfortunately, there is little or no overlap between the series of meteorological observations from the various Halley stations. This makes it difficult to assess the impact of station moves on the composite temperature time series. To address this problem retrospectively, two automatic weather stations (AWSs) were operated close to the sites of former Halley stations following the move of observing programs from Halley $\mathrm{V}$ to Halley VI in 2012. The locations of these stations are given in Table 2 and are shown on Fig. 2. AWS A was installed at a near-coastal location. Although the absolute location of this AWS is not the same as that of any of the former Halley stations, it can be seen by reference to Fig. 2 that the AWS occupies a location relative to the 2015 coastline that is similar to that of Halley I-III relative to the 1959-85 coastlines. We thus argue that, for the purposes of studying spatial temperature gradients across the ice shelf, measurements from this AWS can be used as a proxy for Halley I-III. The second station, AWS B, was installed close to the location occupied by Halley $\mathrm{V}$ at the time that station closed. Together with the observations from Halley VI station, these measurements provide, for the first time, an indication of the magnitude of spatial temperature gradients across the Brunt Ice Shelf.

The stations measured temperature at a nominal height of $2 \mathrm{~m}$ using a platinum resistance thermometer in a naturally ventilated radiation shield. Wind speed and direction were measured using an R. M. Young Co. Aerovane sensor at a nominal height of $3 \mathrm{~m}$. The sensors were sampled every $10 \mathrm{~s}$ and 10-min averages of these samples were recorded. To minimize the impact of radiation errors we have only used AWS temperature data on occasions when the AWS measured a wind speed of $2 \mathrm{~m} \mathrm{~s}^{-1}$ or greater (Genthon et al. 2011).

\section{c. Statistical changepoint detection}

We use the two-sided Mann-Whitney $U$ test, which is also called the Wilcoxon rank-sum test, to test the null hypothesis that the Halley temperature time series is homogeneous. The null hypothesis is rejected if the $p$ value, calculated from the $U$
TABLE 2. Positions and periods of operation of the two AWSs used in this study.

\begin{tabular}{lccc}
\hline \hline AWS name & Position $(\operatorname{Jan} 2014)$ & Start date & End date \\
\hline AWS A & $75.55^{\circ} \mathrm{S}, 27.45^{\circ} \mathrm{W}$ & 11 Mar 2013 & 24 Jan 2017 \\
AWS B & $75.58^{\circ} \mathrm{S}, 26.79^{\circ} \mathrm{W}$ & 19 Aug 2010 & 8 Jan 2018 \\
\hline
\end{tabular}

statistic and the ranks among two sample periods $x$ and $y$, is less than or equal to 0.05 , that is, the temperature data from the two sample periods do not have the same distribution and median values (Gibbons and Chakraborti 2011). Note that the MannWhitney $U$ test is the nonparametric equivalent of the twosample Student's $t$ test. While the $t$ test assumes that two sample groups come from a $t$-distributed population, the Mann-Whitney $U$ test does not require assumptions about the distributions of the populations.

To reduce the large variation associated with the highfrequency component of the Halley composite record and to remove the diurnal cycle and serial correlation induced by daily data, the 3-hourly Halley temperature records are first averaged to monthly means. To make sure the samples are independent of each other (a requirement of the MannWhitney $U$ test), the monthly mean temperature time series are then deseasonalized by subtracting the annual cycle calculated over the whole of the time series. We find that the deseasonalized temperature anomaly time series has no statistically significant autocorrelation, and therefore the samples can be regarded as independent.

To estimate the uncertainty associated with the changepoints, the Mann-Whitney $U$ test is applied to the monthly temperature anomaly time series with a forward running window that varies in size. More specifically, we assume that the temperature anomaly time series is $T(i)$, where $i=1,2,3, \ldots$, $N$. For a given $i$, an equal number of samples, $m$, are taken from $T$ on both sides of $i$, which forms a pair of subsamples of equal length. The two-sided Mann-Whitney $U$ test is then applied to test the similarity of their distributions and the $p$ value is calculated accordingly. The same calculation is repeated for each $i$ as $i$ takes its value from $m$ to $N-m$. To account for uncertainty of the temporal location of a sudden shift, we set $m$ to increase from $m_{0}$ to $N /(k+1)$, where $m_{0}$ is the minimum number of samples required for a subsample group to have a meaningful median value and $k$ is the most likely total number of sudden jumps we would expect in the time series $T$. As such, the MannWhitney $U$ test would have to be applied for $N /(k+1)-m_{0}+$ 1 times for a given temporal location $i$. If the number of the $p$ values that are $\leq 0.05$ accounts for $95 \%$ or more of the total number of tests, the temporal location $i$ is regarded as a potential changepoint (i.e., the median value before this point differs statistically from that after this point).

Our sensitivity tests suggest that the results remain qualitatively similar for $m_{0} \in[24,48]$ and $k \in[2,4]$. We set $m_{0}=36$ and $k=2$ for the results presented in section 4 a.

\section{d. High-resolution regional atmospheric modeling}

To place the point measurements from the Halley stations and from the AWSs into a wider spatial context, we have 


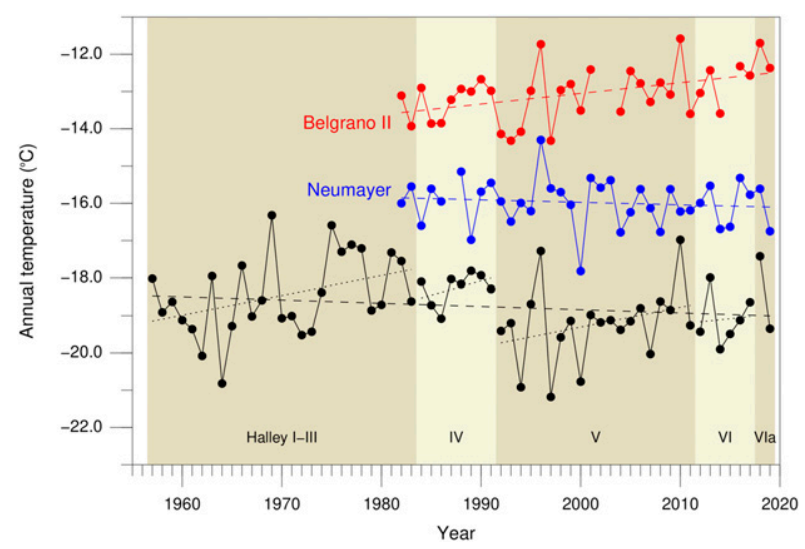

FIG. 5. Time series of annual mean temperature at Halley (black), Belgrano II (red), and Neumayer (blue). Best-fit linear trends for each station are shown as dashed lines, with trends for each of the Halley component records shown as dotted lines.

carried out a high-resolution atmosphere-only model simulation of the Brunt Ice Shelf and surrounding area for 2015, using the nested configuration of version 11.1 of the Met Office Unified Model (MetUM). The computational cost of running such a model is high, which restricted us to running a 1-yr simulation. We chose to simulate the year 2015 as AWS measurements were available for model validation during this period and local meteorological conditions were close to average. In particular, the fractions of winds from the easterly $\left(50^{\circ}-\right.$ $\left.120^{\circ}\right)$ and westerly $\left(230^{\circ}-300^{\circ}\right)$ wind sectors $(61 \%$ and $23 \%$ respectively) were similar to those from the whole of the composite Halley record (58\% and $23 \%$ respectively).

The MetUM is a numerical weather prediction model, which uses nonhydrostatic dynamics and a semi-implicit semiLagrangian method to represent advection (Walters et al. 2017). Our model setup is adapted from that used by Gilbert et al. (2020), who demonstrated that this model configuration produced a good simulation of near-surface meteorology over the Larsen Ice Shelf on the western side of the Weddell Sea. It has an inner domain with a horizontal resolution of $1.5 \mathrm{~km}$ (consisting of $250 \times 250$ grid points), which covers the Brunt Ice Shelf and surrounding area (see Fig. 1 for location). This domain is nested within a larger outer domain with a horizontal resolution of $4 \mathrm{~km}$ (consisting of $200 \times 200$ grid points), which covers a much larger part of the area surrounding the Brunt Ice Shelf. Both domains have 70 vertical levels up to an altitude of $40 \mathrm{~km}$. To construct a broadly reasonable coastline of the Brunt Ice Shelf in the innermost domain for the 2015 period, the model coastline and orography was revised using an up-to-date digital elevation model based on the TerraSAR-X Add-On for Digital Elevation Measurement (TanDEM-X) 90-m digital elevation model (DLR 2018). This model coastline agrees well with the 2012 and 2016 coastlines shown on Fig. 2. To achieve uniform resolution in both domains, the dynamical equations are solved on a rotated latitude-longitude grid. The science configuration of the dynamics and physics schemes used by the nested models is the midlatitude regional atmosphere configuration (RA1-M), which is described by Bush et al. (2020).
TABLE 3. Annual mean temperature trends and $95 \%$ confidence intervals (from a least squares linear fit) for the Halley composite record and for each of the component Halley stations. Halley I-III were all close together and are treated as a single record. Also shown are trends from the nearest-neighbor stations, Belgrano II and Neumayer. Trends significant at $10 \%$ or better are indicated by one asterisk; $5 \%$ or better is indicated by two asterisks.

\begin{tabular}{lccc}
\hline \multicolumn{1}{c}{ Station } & Start year & End year & Trend $\left({ }^{\circ} \mathrm{C}\right.$ decade $\left.{ }^{-1}\right)$ \\
\hline Halley (composite) & 1957 & 2019 & $-0.086 \pm 0.162$ \\
Halley I-III & 1957 & 1983 & $+0.528 \pm 0.518^{*}$ \\
Halley IV & 1984 & 1991 & $+0.749 \pm 1.262$ \\
Halley V & 1992 & 2011 & $+0.527 \pm 0.758$ \\
Halley VI & 2012 & 2017 & $+0.283 \pm 3.575$ \\
Halley (composite) & 1982 & 2019 & $-0.137 \pm 0.281$ \\
Belgrano II & 1982 & 2019 & $+0.293 \pm 0.251^{* *}$ \\
Neumayer & 1982 & 2019 & $-0.067 \pm 0.189$ \\
\hline
\end{tabular}

The required start data and lateral boundary conditions for the nested domains are supplied by a global version run of the MetUM at N512 resolution $(1024 \times 768$ grid points, equivalent to a horizontal resolution of $\sim 25 \mathrm{~km}$ at midlatitudes), which is itself initialized by the ERA-Interim reanalysis (Dee et al. 2011). Sea ice and sea surface temperature fields for all domains are also taken from the reanalysis. The model is used to produce a series of $24 \mathrm{~h}$ forecasts, initialized every $12 \mathrm{~h}$, for the period from 1200 UTC 31 December 2014 to 0000 UTC 31 December 2015. The initial $12 \mathrm{~h}$ of each forecast is discarded as spinup, with the remaining part of the forecasts concatenated together to form a continuous time series for 2015 .

\section{Results}

\section{a. Changepoint analysis}

Figure 5 shows the composite time series of annual average temperature from measurements at all of the Halley stations, with the shorter records from the nearest-neighbor stations, Belgrano II and Neumayer, shown for comparison. A least squares linear fit to the entire Halley record gives an overall cooling trend of $-0.086^{\circ} \pm 0.162^{\circ} \mathrm{C}$ per decade (not statistically significant). However, if the record is split into segments for each of the Halley stations (but counting Halley I-III as a single location, as all three stations were close to each other) then each segment (apart from the very short record from Halley VIa) displays a warming trend (Table 3). Visual inspection of the record suggests that there is a substantial negative jump in temperature coincident with the move from Halley IV to Halley V that is largely responsible for the overall cooling trend in the composite series. There is little sign of this jump in the records from the nearest neighbor stations, suggesting that the jump in the Halley record could be an artifact associated with the relocation of the station. To investigate this possibility further we have applied the formal changepoint detection methodology described in section $3 c$ to the Halley composite temperature record.

Figure 6a shows the time series of monthly anomalies of Halley composite temperature together with the temporal locations of the changepoints that are detected by the Mann-Whitney $U$ test. 

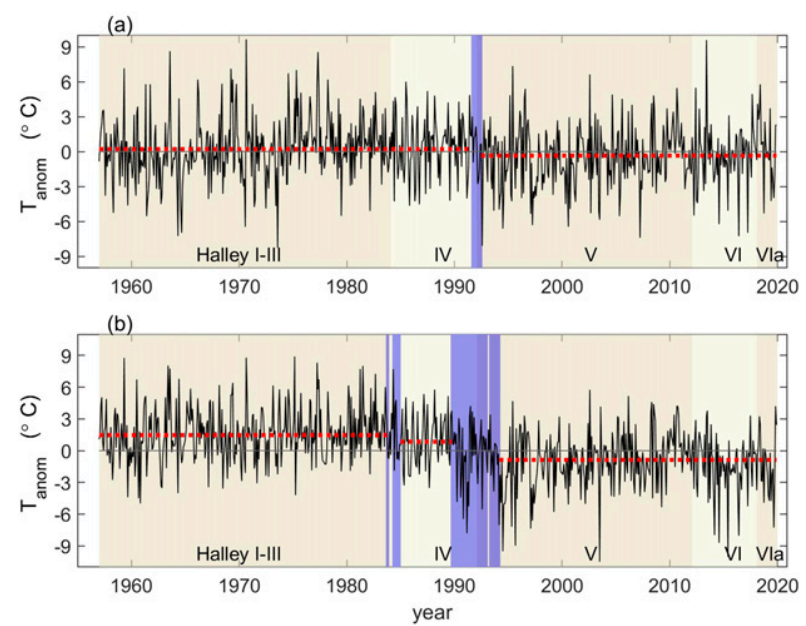

FIG. 6. Deseasonalized Halley monthly temperature anomalies (black lines) for (a) all wind directions and (b) winds from the westerly sector only. The periods associated with each of the Halley stations are indicated by the shaded regions. The blue-shaded vertical bars indicate the times between which significant changepoints are detected using the Mann-Whitney $U$ test. The red dashed horizontal lines show the median of the temperature anomalies on either side of the detected changepoints.

The test suggests that a statistically significant shift in the median of the time series occurred sometime during the period of August 1991 to June 1992. The difference between the temperature anomalies before August 1991 and after January 1992 is $-0.6^{\circ} \mathrm{C}$ for the median and $-0.7^{\circ} \mathrm{C}$ for the mean, which indicates a sudden downward shift of the temperature record around this time. In addition, the Mann-Whitney $U$ test indicates that January 1992 has the smallest $p$ value overall (0.0015). It therefore represents the most likely changepoint across the entire record, which corresponds exactly with the station move from Halley IV to Halley V. Application of the same technique to the Neumayer and Belgrano II records did not identify any statistically significant changepoints.

Figure $6 \mathrm{~b}$ shows the results of the Mann-Whitney test for the time series of temperature anomalies calculated only for occasions when the wind was in the westerly sector (i.e., $230^{\circ}-$ $300^{\circ}$ ). For this time series, significant shifts of the median are detected over two periods. The most significant changepoint detected occurred between September 1989 and February 1994, which also encompasses the station relocation from Halley IV to Halley V. The second changepoint occurred between September 1983 and November 1984, which encompasses the relocation from Halley III to Halley IV. Both changepoints are associated with a negative jump in temperature, a median and mean differences of $-2.2^{\circ}$ and $-2.6^{\circ} \mathrm{C}$, respectively, for the changepoint from Halley IV to Halley $\mathrm{V}$. These values are nearly 4 times those calculated for all wind directions (Fig. 6a). The same changepoint detection analysis was performed for the easterly wind sector; that is, the temperature anomalies were calculated only for those records when the $10-\mathrm{m}$ wind directions were in the sector $50^{\circ}-120^{\circ}$, but no statistically significant changepoint was detected. These results suggest that negative jumps in temperature that correspond with station relocations may have contributed toward the apparent negative trend in the Halley composite temperature record. In addition, the test reveals that the sudden drops in temperature around 1990-93 and 1983-84 are largely associated with the westerly wind sector (i.e., those occasions when the winds arriving at the station had a relatively short fetch from the coast).

\section{b. Spatial variability in temperature from $A W S$ measurements}

The analysis presented in previous section suggests that the composite Halley record is not homogeneous. In this section, we use measurements from Halley VI and the two AWSs to gain insight into the magnitudes of spatial temperature gradients across the Brunt Ice Shelf and to determine whether they can explain the observed inhomogeneity.

Table 4 shows the mean temperature differences between Halley VI and the two AWSs for the calendar year 2015. The distance between AWS A and AWS B is comparable to that between AWS B and Halley VI. However, the temperature difference between the former pair of stations is greater than that between the latter, indicating that the temperature gradient across the ice shelf is largely concentrated into the region between AWS B and the coast. The temperature difference between both pairs of stations increases relative to its mean value when the wind is from the westerly sector and decreases relative to the mean for easterly sector winds. This variation of temperature gradient with wind direction is consistent with our suggestion (in section 2) that the strongest temperature gradients will be seen when westerly winds advect warmed air over the ice shelf. Such gradients will be strongest in the nearcoastal zone and will diminish with increasing distance from the coast as the warm air comes into equilibrium with the ice shelf surface. The larger temperature gradients observed under westerly flow also explain why our statistical analysis (section 4a) detected larger temperature jumps associated with station moves when the analysis was restricted to periods with westerly sector winds.

\section{c. Spatial variability in temperature from high-resolution modeling}

In this section, we use the results of the high-resolution model simulation described in section $3 d$ to place the AWS measurements into a broader spatial context and hence gain a better understanding of the processes that control spatial temperature gradients over the ice shelf. Before doing this, we compare the results of the model simulation with observations from the two AWSs and Halley VI to confirm that the model is able to capture the spatial and temporal variability of near-surface meteorological variables across the ice shelf realistically.

We extracted 3-hourly time series of model 1.5-m temperature and 10-m wind speed at the locations of the two AWSs and Halley VI using bilinear interpolation. Modeled 10-m wind speeds at the AWS locations were then corrected to the AWS measurement height (taken to be $2.5 \mathrm{~m}$ ) assuming a logarithmic wind profile with a roughness length of $0.1 \mathrm{~mm}$ (King 1990). No correction was necessary at Halley VI, where wind 
TABLE 4. Mean temperature differences $\left({ }^{\circ} \mathrm{C}, \pm 1\right.$ standard deviation) between Halley VI and the two AWSs during the calendar year 2015. Also shown are the temperature differences between corresponding locations in the high-resolution model simulation (see section 4c). Means and standard deviations are calculated from 3-hourly measurements (or model data) at each location. Easterly sector wind directions are $50^{\circ}-120^{\circ}$, and westerly wind directions are $230^{\circ}-300^{\circ}$, with the wind direction at Halley VI used to define the sector. The number of AWS data points within each sector is indicated at the head of the column for the sector. To exclude data that may have been affected by radiation errors, temperature differences have been calculated only on occasions when the AWS or model wind speed was $\geq 2 \mathrm{~m} \mathrm{~s}^{-1}$.

\begin{tabular}{lccccc}
\hline \hline & & & \multicolumn{2}{c}{ Wind directions } \\
\cline { 3 - 6 } Diff & Distance & Source & All; $N=2916$ & Easterly; $N=1810$ & Westerly; $N=503$ \\
\hline AWS A-AWS B & $18.6 \mathrm{~km}$ & AWS & $0.63 \pm 1.50$ & $0.50 \pm 1.21$ & $1.55 \pm 2.15$ \\
& & Model & $0.59 \pm 1.17$ & $0.30 \pm 0.92$ & $1.20 \pm 1.34$ \\
AWS B-Halley VI & $18.1 \mathrm{~km}$ & AWS & $0.36 \pm 1.23$ & $0.20 \pm 0.88$ & $0.49 \pm 1.65$ \\
& & Model & $0.07 \pm 1.06$ & $-0.11 \pm 0.78$ & $0.52 \pm 1.30$ \\
\hline
\end{tabular}

speed was measured at the standard 10-m height. These time series were then compared with the corresponding AWS data to calculate correlation coefficients and model biases (Table 5). The high correlation coefficients demonstrate that the model is accurately capturing the temporal variability of both temperature and wind speed. However, model temperatures are biased cold at all three locations. Wind speed and direction are simulated remarkably accurately at all three sites. Figure 7 shows wind roses for Halley VI during 2015, based on model output and observations. The model reproduces the observed bimodal distribution of wind directions, although model winds are more strongly clustered around the two modal directions than is seen in the observations. Both modal directions in the model are also rotated around $10^{\circ}$ anticlockwise from their observed values. Despite these differences, the modeled frequencies of occurrence of winds from the easterly $\left(50^{\circ}-120^{\circ}\right)$ and westerly $\left(230^{\circ}-300^{\circ}\right)$ sectors $(65 \%$ and $21 \%$ respectively) are close to those observed at Halley VI (61\% and $23 \%$ respectively).

The model is thus capable of simulating near-surface conditions across the Brunt Ice Shelf fairly realistically. Modeled near-surface temperatures are biased cold by $1^{\circ}-2^{\circ} \mathrm{C}$, which probably results from an imperfect representation of processes such as clouds and near-surface mixing (Gilbert et al. 2020; King et al. 2015; van Wessem et al. 2014). While the model correctly simulates a larger mean temperature difference between AWS A and AWS B than between AWS B and Halley
VI, the absolute values of the model temperature difference between each of these station pairs are somewhat smaller than those derived from AWS observations over the same period (Table 4). The most likely cause of this difference is that the model uses a rather coarse-resolution $(\sim 80 \mathrm{~km})$ sea ice product as a boundary condition, which is not capable of resolving the narrow coastal polynya to the west of the Brunt Ice Shelf (Fig. 3c). In the model, therefore, near-surface air arriving at the coast of the ice shelf from the west will not have been warmed to the same extent that it is in reality. Despite underestimating the absolute temperature differences, the model reproduces the observed increase in the temperature differences when the wind is in the westerly sector reasonably accurately. Figure 8 shows modeled annual mean $1.5-\mathrm{m}$ temperatures across the Brunt Ice Shelf relative to the modeled temperature at Halley VI. Temperature gradients are large in the immediate vicinity of the model coast, becoming smaller farther inland. Isotherms in the coastal region closely follow the coast while, over the interior of the ice shelf, the main temperature gradient is directed in an approximately southwesterly - northeasterly direction. The large temperature gradient seen along the southeastern boundary of the ice shelf marks the region where the flat ice shelf meets the steeply sloping continental ice. Here, temperature rises with increasing elevation as a result of the deep, persistent surface inversion that forms over the flat ice shelf intersecting the steep coastal slope (King et al. 1998).

TABLE 5. Validation statistics for modeled 1.5-m temperature and 10-m wind speed at the two AWS locations and at Halley VI, calculated from 3 -hourly data for 2015 . Uncertainty bounds shown on the means are \pm 1 standard error. To exclude temperature data that may have been affected by radiation errors, only occasions when the AWS wind speed was $\geq 2 \mathrm{~m} \mathrm{~s}^{-1}$ have been included in the analysis for temperature.

\begin{tabular}{|c|c|c|c|c|c|}
\hline & No. of data points & Correlation coef & Model mean & Model bias & RMSE \\
\hline \multicolumn{6}{|c|}{$1.5-\mathrm{m} T\left({ }^{\circ} \mathrm{C}\right)$} \\
\hline AWS A & 2302 & 0.94 & $-18.75 \pm 0.21$ & -2.46 & 4.16 \\
\hline AWS B & 2004 & 0.94 & $-20.17 \pm 0.22$ & -2.46 & 4.24 \\
\hline Halley VI & 2742 & 0.94 & $-21.22 \pm 0.21$ & -1.68 & 4.20 \\
\hline \multicolumn{6}{|c|}{$10-\mathrm{m}$ wind speed $\left(\mathrm{m} \mathrm{s}^{-1}\right)$} \\
\hline AWS A & 2909 & 0.85 & $6.22 \pm 0.07$ & 0.74 & 2.42 \\
\hline AWS B & 2909 & 0.84 & $5.99 \pm 0.07$ & 0.88 & 2.78 \\
\hline Halley VI & 2909 & 0.90 & $6.85 \pm 0.08$ & -0.24 & 1.99 \\
\hline
\end{tabular}



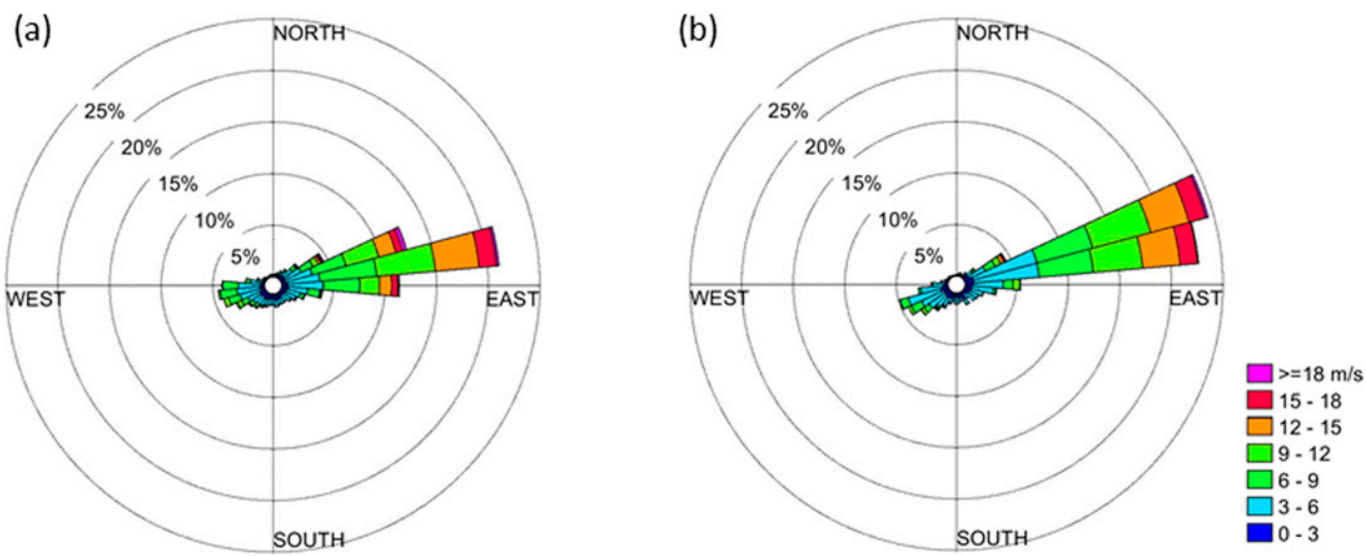

FIG. 7. Wind roses for Halley VI for 2015 from (a) observations and (b) the MetUM run.

Figures 9 and 10 show the mean temperature fields for occasions when the observed wind at Halley VI was in the easterly and westerly sectors, respectively. With easterly winds (Fig. 9), large temperature gradients are confined to a very narrow coastal strip while temperature gradients over the interior of the ice shelf are small, with isotherms oriented roughly east-west. By contrast, with westerly sector winds (Fig. 10), a strong temperature gradient directed approximately perpendicular to the west

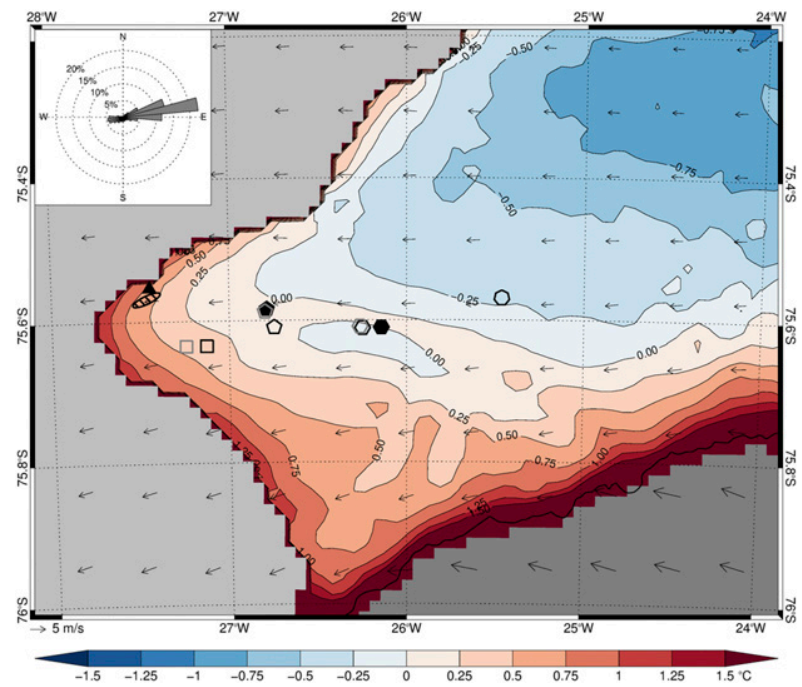

FIG. 8. Mean modeled 1.5-m temperature for 2015, expressed as a difference from its value at the location of Halley VI, with mean 10-m wind vectors overlain. Ocean and sea ice points have been masked light gray, and terrain above 100-m elevation has been masked dark gray. The inset wind rose shows the observed wind direction distribution at Halley VI. Filled symbols indicate the locations of stations that were active in 2015 as follows: Filled triangle-AWS A; filled pentagon-AWS B; filled hexagon-Halley VI. Open symbols indicate analog locations for the initial (black symbol) and final (gray symbol) positions of Halley I-V and Halley VIa relative to the 2015 coastline as follows: shaded ellipse-range of positions occupied by Halley I-III; squares-Halley IV; pentagons-Halley V; heptagon-Halley VIa. coast of the ice shelf extends inland from this coast. The model results thus support (at least qualitatively) our hypothesis that spatial temperature gradients across the ice shelf largely result from the low-level advection of warmed air associated with westerly sector winds and the subsequent cooling of this air as it flows eastward across the ice shelf.

In addition to the locations of the stations that were active in 2015, Figs. 8-10 also indicate approximate "analog" positions of Halley at the times that the station was moved. These locations were selected using a procedure described in the appendix so that their positions relative to the 2015 coastline were similar to that of the actual station relative to the coastline at the time the station was operational. Table 6 lists the modeled annual average temperature differences between these analog positions. Temperature differences between Halley I-III are small as the analog locations of these stations lie close together. Larger temperature differences are seen between Halley III and IV, and between Halley IV and V, reflecting the larger

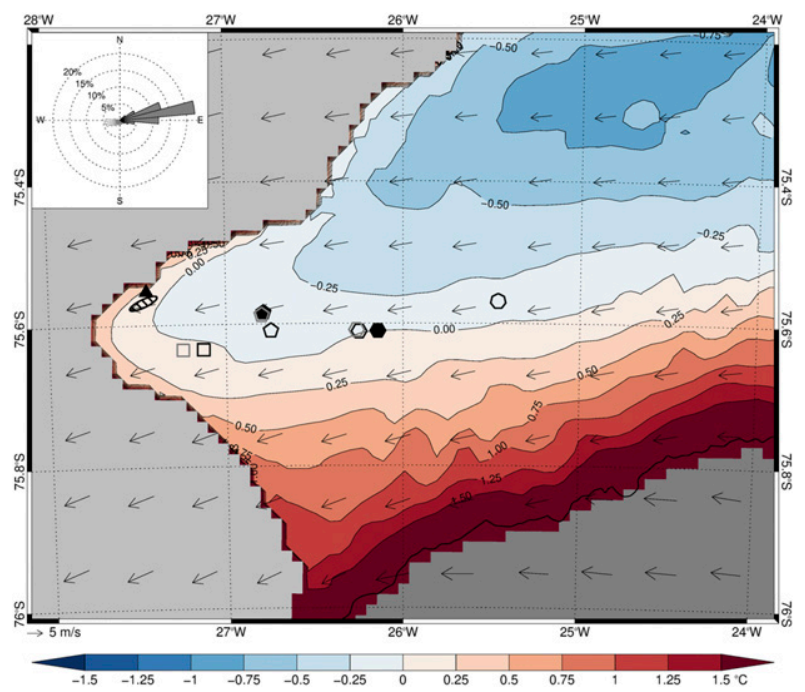

FIG. 9. As in Fig. 8, but conditionally averaged for easterly sector winds (sector shaded gray on the inset wind rose) at Halley VI. 


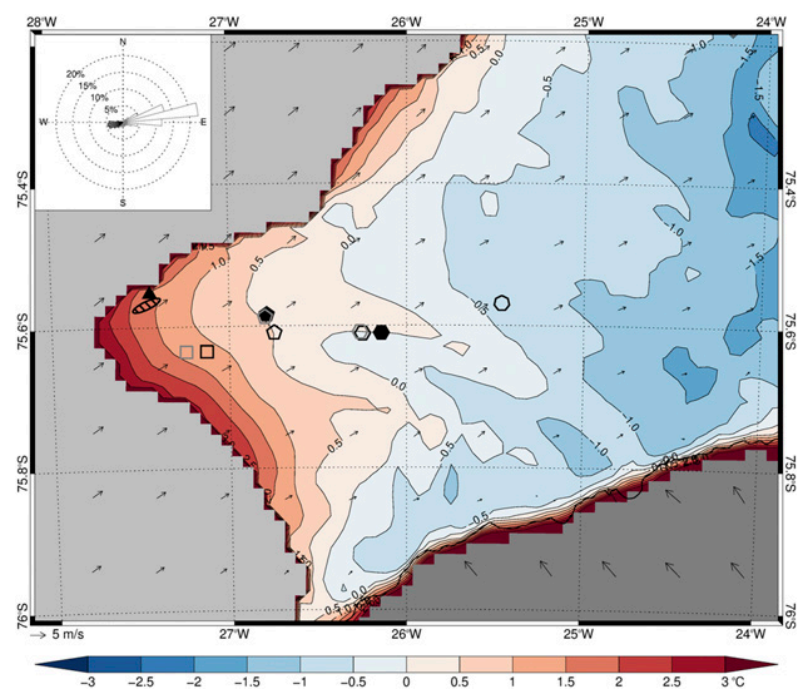

FIG. 10. As in Fig. 8, but conditionally averaged for westerly sector winds (sector shaded gray on the inset wind rose) at Halley VI.

separations between these stations. Although the move from Halley V to Halley VI resulted in a similar increase in distance from the coast as that from Halley IV to Halley V, the modeled temperature difference between Halley V and Halley VI is very small because, in contrast to previous relocations, the station was moved in a direction that was very closely aligned with the direction of the mean isotherms.

\section{Discussion and conclusions}

Our statistical analysis of the composite Halley temperature record (section $4 \mathrm{a}$ ) identified a changepoint in the record coincident with the move from Halley IV to Halley V in January 1992 , associated with a sudden cooling of around $0.7^{\circ} \mathrm{C}$. No other statistically significant changepoints were detected but when the analysis was restricted to occasions when the wind was blowing from the westerly sector, a second changepoint, with a cooling of around $0.5^{\circ} \mathrm{C}$ was detected at around the time of the move from Halley III to Halley IV in 1983. With the analysis restricted to the westerly sector, the cooling associated with the Halley IV-Halley $\mathrm{V}$ move increases to around $2.0^{\circ} \mathrm{C}$.
The statistical analysis thus provides evidence for inhomogeneity in the composite temperature record and, furthermore, suggests that the temperature jumps associated with station relocations are largely caused by differences in temperature during westerly sector winds.

The AWS observations and the results of the high-resolution model run provide clear evidence for the existence of spatial temperature gradients across the Brunt Ice Shelf that will very likely have led to inhomogeneities in the composite temperature record when the station was moved. The gradients are relatively small when winds blow from the predominant easterly sector but become much larger when winds blow from the secondary westerly sector. Although the frequency of winds from the westerly sector is only around one-third of that from the easterly sector, the enhanced temperature gradient seen with westerly sector winds is sufficiently large to have a clear impact on the annual mean. The temperature gradient is strongest close to the coast and reduces with increasing distance from the coast along the modal direction of the westerly sector winds, consistent with our hypothesis that the temperature gradients are caused by the advection of relatively warm air from the Weddell Sea across the cooler ice shelf.

Table 6 gives an indication of the temperature jumps that we would have expected to see in the composite temperature record assuming that the model accurately reproduces the actual temperature gradients and that the gradients modeled in 2015 are representative of those that prevailed over the whole of the composite record. The table indicates only small temperature differences between Halley I and Halley III, which is consistent with the absence of changepoints in this part of the composite record in our statistical analysis and is to be expected because these stations all occupied similar positions relative to the ice shelf coast. The table further suggests that we should have seen downward jumps in annual mean temperature of $0.3^{\circ}-0.4^{\circ} \mathrm{C}$ associated with both the Halley III-Halley IV move and the Halley IV-Halley V move. Our statistical analysis only detects a changepoint associated with the latter move, with an associated temperature change of about $-0.7^{\circ} \mathrm{C}$ (Fig. 6a). This is very close to the modeled temperature difference between Halley III and Halley V $\left(-0.69^{\circ} \mathrm{C}\right.$; Table 6) and suggests that there may be an inhomogeneity associated with the Halley III-Halley IV move, which we were unable to detect statistically due to the high level of interannual variability in the record. Our detection of a changepoint associated with the

TABLE 6. Modeled annual mean temperature differences in 2015 between 2015 analog locations of the historical Halley stations at the times of station relocations. Analog locations have been calculated so that the analog station location lies in a similar position with respect to the 2015 coastline to that occupied by the actual station relative to the coastline at the time of the station move (see the text and the appendix for details).

\begin{tabular}{llcr}
\hline \hline Old station & New station & Change in distance from coast $(\mathrm{km})$ & $T_{\text {new }}-T_{\text {old }}\left({ }^{\circ} \mathrm{C}\right)$ \\
\hline Halley I & Halley II & +1 & -0.15 \\
Halley II & Halley III & -2 & 0.04 \\
Halley III & Halley IV & +7 & -0.35 \\
Halley IV & Halley V & +11 & -0.34 \\
Halley V & Halley VI & +10 & -0.10 \\
Halley VI & Halley VIa & +15 & -0.28 \\
\hline
\end{tabular}


Halley III - Halley IV move when we restricted our analysis to the westerly wind sector (Fig. 6b) provides some support for this view.

In principle, a model simulation could be used as the basis for determining adjustments to the various sections of the composite record that would remove the inhomogeneities associated with station relocations. However, for reasons discussed above, the 1-yr model simulation presented here underestimates the observed gradients (Table 4) and, furthermore, does not provide any information on their interannual variability. Over the three years (2014-16) of overlapping data from AWS A and Halley VI the mean temperature difference between these stations was $1.61^{\circ} \mathrm{C}$, varying between $1.45^{\circ} \mathrm{C}$ in 2015 and $1.90^{\circ} \mathrm{C}$ in 2016 . There would thus be large uncertainties in adjustments derived from the model simulation presented here but a multiyear simulation that used a higher-resolution representation of sea ice (e.g., Alexander et al. 2017; Zentek and Heinemann 2020) could possibly reduce these uncertainties.

A simpler approach to homogenization would be to remove the temperature jumps that we detected in our statistical analysis. We do not recommend this approach due to the difficulties inherent in detecting changepoints in a temperature record that exhibits high interannual variability. However, for illustrative purposes, we examined the effect of removing the $-0.7^{\circ} \mathrm{C}$ jump associated with the Halley IV-Halley V move from the composite time series. This changed the trend calculated over the whole record from a weak cooling (Table 3) to a weak (and not statistically significant) warming.

As discussed in section 1, the lack of suitable "nearest neighbor" station records has precluded us from using standard homogenization procedures, which examine the differences between a candidate record and a "reference" record formed as a composite mean of the neighboring station records. One possible approach to overcoming this difficulty would be to train a machine learning system to reproduce a homogeneous subsection of the Halley record (e.g., the record from Halley V) using climate observations from other Antarctic and sub-Antarctic stations as inputs. The trained system could then be used to produce an artificial reference record for the whole of the time period covered by the Halley record.

Our analysis has demonstrated that at least one of the Halley station relocations has introduced an inhomogeneity into the composite temperature record that is sufficiently large to change the sign of the long-term temperature trend calculated from the record. We therefore recommend that the composite Halley temperature record should not be used in long-term climatological analyses without careful consideration of its inhomogeneity. Our study suggests that the subsections of the record from Halley I to III (1957-83) and from Halley V to VI (1992-2017) are reasonably homogeneous within themselves but that a significant inhomogeneity is associated with the move from Halley IV to Halley V in 1992, and a second inhomogeneity may be associated with the Halley III to Halley IV move in 1984. Model results (Table 6) suggest that the move from Halley VI to Halley VIa may have introduced a further inhomogeneity, but the record from Halley VIa is, as yet, too short to confirm this. The existence of temperature jumps associated with station relocation in an environment that appears superficially homogeneous emphasizes the need to maintain overlapping records during station relocations when a record has long-term climatological value.

Last, we note that the composite Halley temperature record has been used in a number of gridded reconstructions of Antarctic temperatures (Doran et al. 2002; Chapman and Walsh 2007; Monaghan et al. 2008; Nicolas and Bromwich 2014). A common feature seen in the maps of temperature trends produced from these reconstructions is a large area of cooling trend stretching inland from the coastal region around Halley, which contrasts with neutral or weak warming trends in adjoining parts of East Antarctica. Given the sparseness of the Antarctic climate observing network, it seems likely that the artificial cooling in the inhomogeneous composite Halley temperature record will have contributed to this feature and we therefore question its robustness. Any future efforts to produce gridded Antarctic temperature reconstructions need to recognize the inhomogeneity of the Halley record.

Acknowledgments. This study was funded by the Natural Environment Research Council as part of the British Antarctic Survey's "Polar Science for Planet Earth" program.

Data availability statement. Climate data used in this study are available from the publicly accessible sources listed in section 3a. Metadata for Halley can be found in annual meteorological data reports from the station, which are available from British Antarctic Survey Archives (https://www.bas.ac.uk/team/ business-teams/information-services/archives/) as report series $\mathrm{AD} 6 / 2 \mathrm{HB}$ and AD6/2Z. Data from the automatic weather stations (https://doi.org/10.5285/4e963d9b-da5d-43d5-a605-fc44ead63d97) and model output from the MetUM run (https://doi.org/10.5285/ 20f3bf27-bf33-4c21-8164-005667b2ddb8) can be accessed through the U.K. Polar Data Centre (https://www.bas.ac.uk/data/uk-pdc/).

\section{APPENDIX}

\section{Determination of 2015 Analog Positions for the Halley Station Locations}

The goal of the selection of 2015 analog positions for Halley locations was to find locations, relative to the 2015 coastline, that were similar to that of the actual station relative to the coastline at the time that the station was operational. Because the mean temperature gradients across the relevant parts of the Brunt Ice Shelf are most strongly affected by the distance to the coastline when westerly winds occur (Figs. 8-10), the analog positions were selected so that the distances to the 2015 coastline across the range of directions spanned by the westerly wind sector $\left(230^{\circ}-300^{\circ}\right)$ most closely matched the distances from the location of Halley to the coastline at that time. This was achieved by minimizing the mean-square difference between the distances from the location of Halley to the most nearly contemporaneously surveyed coastline at $1^{\circ}$ intervals across the directions from $225.5^{\circ}$ to $304.5^{\circ}$ and the distance to the 2015 coastline across the same range of directions, 
TABLE A1. Analog positions for Halley stations in specific years, together with the year of the coastline survey used to establish the analog position.

\begin{tabular}{cccc}
\hline \hline Station & Year & Analog position & $\begin{array}{c}\text { Year of } \\
\text { coastline } \\
\text { survey }\end{array}$ \\
\hline Halley I & 1959 & $75.57779^{\circ} \mathrm{S}, 27.51105^{\circ} \mathrm{W}$ & 1959 \\
& 1968 & $75.57558^{\circ} \mathrm{S}, 27.51011^{\circ} \mathrm{W}$ & 1968 \\
Halley II & 1968 & $75.56624^{\circ} \mathrm{S}, 27.40312^{\circ} \mathrm{W}$ & 1968 \\
& 1973 & $75.55995^{\circ} \mathrm{S}, 27.41644^{\circ} \mathrm{W}$ & 1973 \\
Halley III & 1974 & $75.56015^{\circ} \mathrm{S}, 27.43677^{\circ} \mathrm{W}$ & 1973 \\
& 1982 & $75.57502^{\circ} \mathrm{S}, 27.53229^{\circ} \mathrm{W}$ & 1985 \\
Halley IV & 1984 & $75.63516^{\circ} \mathrm{S}, 27.12809^{\circ} \mathrm{W}$ & 1985 \\
& 1991 & $75.63538^{\circ} \mathrm{S}, 27.24403^{\circ} \mathrm{W}$ & 1990 \\
Halley V & 1992 & $75.60974^{\circ} \mathrm{S}, 26.74663^{\circ} \mathrm{W}$ & 1990 \\
& 2011 & $75.58763^{\circ} \mathrm{S}, 26.79825^{\circ} \mathrm{W}$ & 2011 \\
Halley VI & 2012 & $75.61134^{\circ} \mathrm{S}, 26.24789^{\circ} \mathrm{W}$ & 2012 \\
& 2017 & $75.60929^{\circ} \mathrm{S}, 26.26232^{\circ} \mathrm{W}$ & 2017 \\
Halley VIa & 2017 & $75.56910^{\circ} \mathrm{S}, 25.46319^{\circ} \mathrm{W}$ & 2017 \\
\hline
\end{tabular}

weighted in proportion to the frequency of wind occurrence within each $10^{\circ}$ wind direction bin. The minimization was performed using the following procedure:

1) The distance from the location of Halley in a specific year to the most nearly contemporaneously surveyed coastline was measured across the directions from $225.5^{\circ}$ to $304.5^{\circ}$ at $1^{\circ}$ intervals.

2) The location of Halley was then adjusted by the estimated motion of Halley itself for each year between that year and 2015. For each year, the distances from the adjusted location to the 2015 coastline across the same range of directions was measured. An initial estimate for the analog position was made by choosing the adjusted location that minimized the mean squared difference between these coastline distances, weighted in proportion to the frequency of wind occurrence within each $10^{\circ}$ bin.

3) A $51 \times 51$ grid (initially with a $1-\mathrm{km}$ gridpoint spacing) centered on the estimated analog position was defined. For each point in the grid, the mean weighted squared difference of estimated distances to the coastline was calculated.

4) The estimated analog position was adjusted by moving it halfway from the current estimate to the gridpoint minimum identified above. The gridpoint spacing was halved, and the above step was repeated.

5) The above process was repeated until the estimated analog position moved by less than $1 \mathrm{~m}$ between iterations or the gridpoint spacing was reduced to less than $1 \mathrm{~m}$.

The analog positions identified by the above procedure are shown in Table A1.

\section{REFERENCES}

Alexander, S. P., A. Orr, S. Webster, and D. J. Murphy, 2017: Observations and fine-scale model simulations of gravity waves over Davis, East Antarctica $\left(69^{\circ} \mathrm{S}, 78^{\circ} \mathrm{E}\right)$. J. Geophys. Res. Atmos., 122, 7355-7370, https://doi.org/10.1002/2017JD026615.
Anderson, P. S., 1993: Evidence for an Antarctic winter coastal polynya. Antarct. Sci., 5, 221-226, https://doi.org/10.1017/ S0954102093000288.

Anderson, R., D. H. Jones, and G. H. Gudmundsson, 2014: Halley Research Station, Antarctica: Calving risks and monitoring strategies. Nat. Hazards Earth Syst. Sci., 14, 917-927, https:// doi.org/10.5194/nhess-14-917-2014.

Bush, M., and Coauthors, 2020: The first Met Office Unified Model-JULES Regional Atmosphere and Land configuration, RAL1. Geosci. Model Dev., 13, 1999-2029, https:// doi.org/10.5194/gmd-13-1999-2020.

Chapman, W. L., and J. E. Walsh, 2007: A synthesis of Antarctic temperatures. J. Climate, 20, 4096-4117, https://doi.org/10.1175/ JCLI4236.1.

Culf, A. D., 1989: Acoustic sounding of the atmospheric boundary layer at Halley, Antarctica. Antarct. Sci., 1, 363-372, https:// doi.org/10.1017/S0954102089000544.

Dee, D. P., and Coauthors, 2011: The ERA-Interim reanalysis: Configuration and performance of the data assimilation system. Quart. J. Roy. Meteor. Soc., 137, 553-597, https://doi.org/ 10.1002/qj.828.

DLR, 2018: TanDEM-X digital elevation model (DEM)-Global, $90 \mathrm{~m}$. German Aerospace Center (DLR), https://doi.org/ 10.15489/ju28hc7pui09.

Doran, P. T., and Coauthors, 2002: Antarctic climate cooling and terrestrial ecosystem response. Nature, 415, 517-520, https:// doi.org/10.1038/nature710.

Fiedler, E. K., T. A. Lachlan-Cope, I. A. Renfrew, and J. C. King, 2010: Convective heat transfer over thin ice covered coastal polynyas. J. Geophys. Res., 115, C10051, https://doi.org/ 10.1029/2009JC005797.

Genthon, C., D. Six, V. Favier, M. Lazzara, and L. Keller, 2011: Atmospheric temperature measurement biases on the Antarctic Plateau. J. Atmos. Oceanic Technol., 28, 1598-1605, https:// doi.org/10.1175/JTECH-D-11-00095.1.

Gibbons, J. D., and S. Chakraborti, 2011: Nonparametric Statistical Inference. 5th ed. Taylor and Francis/CRC Press, $650 \mathrm{pp}$.

Gilbert, E., A. Orr, J. C. King, I. A. Renfrew, T. Lachlan-Cope, P. F. Field, and I. A. Boutle, 2020: Summertime cloud phase strongly influences surface melting on the Larsen C ice shelf, Antarctica. Quart. J. Roy. Meteor. Soc., 146, 1575-1589, https://doi.org/10.1002/qj.3753.

King, J. C., 1990: Some measurements of turbulence over an Antarctic ice shelf. Quart. J. Roy. Meteor. Soc., 116, 379-400, https://doi.org/10.1002/qj.49711649208.

— - M. J. Varley, and T. A. Lachlan-Cope, 1998: Using satellite thermal infrared imagery to study boundary layer structure in an Antarctic katabatic wind region. Int. J. Remote Sens., 19, 3335-3348, https://doi.org/10.1080/014311698214028.

_- , and Coauthors, 2015: Validation of the summertime surface energy budget of Larsen C Ice Shelf (Antarctica) as represented in three high-resolution atmospheric models. J. Geophys. Res. Atmos., 120, 1335-1347, https://doi.org/ 10.1002/2014JD022604.

König-Langlo, G., J. C. King, and P. Pettre, 1998: Climatology of the three coastal Antarctic stations Dumont d'Urville, Neumayer, and Halley. J. Geophys. Res., 103, $10935-10946$, https://doi.org/ 10.1029/97JD00527.

Markus, T., C. Kottmeier, and E. Fahrbach, 1998: Ice formation in coastal polynyas in the Weddell Sea and their impact on oceanic salinity. Antarctic Sea Ice: Physical Processes, Interactions and Variability, M. O. Jeffries, Ed., Amer. Geophys. Union, 273-292. 
Menne, M. J., and C. N. Williams Jr., 2009: Homogenization of temperature series via pairwise comparisons. J. Climate, 22, 1700-1717, https://doi.org/10.1175/2008JCLI2263.1.

Monaghan, A. J., D. H. Bromwich, W. Chapman, and J. C. Comiso, 2008: Recent variability and trends of Antarctic near-surface temperature. J. Geophys. Res., 113, D04105, https://doi.org/ 10.1029/2007JD009094.

Nicolas, J. P., and D. H. Bromwich, 2014: New reconstruction of Antarctic near-surface temperatures: Multidecadal trends and reliability of global reanalyses. J. Climate, 27, 8070-8093, https://doi.org/10.1175/JCLI-D-13-00733.1.

Raper, S. C. B., T. M. L. Wigley, P. R. Mayes, P. D. Jones, and M. J. Salinger, 1984: Variations in surface air temperatures. Part 3: The Antarctic, 1957-1982. Mon. Wea. Rev., 112, 1341-1353, https:// doi.org/10.1175/1520-0493(1984)112<1341:VISATP>2.0.CO;2.

Renfrew, I. A., and P. S. Anderson, 2002: The surface climatology of an ordinary katabatic wind regime in Coats Land, Antarctica. Tellus, 54, 463-484, https://doi.org/10.3402/tellusa.v54i5.12162.

, J. C. King, and T. Markus, 2002: Coastal polynyas in the southern Weddell Sea: Variability of the surface energy budget. $J$. Geophys. Res., 107, 3063, https://doi.org/10.1029/2000JC000720.

Turner, J., and Coauthors, 2004: The SCAR READER project: Toward a high-quality database of mean Antarctic meteorological observations. J. Climate, 17, 2890-2898, https://doi.org/ 10.1175/1520-0442(2004)017<2890:TSRPTA >2.0.CO;2.
- and Coauthors, 2005: Antarctic climate change during the last 50 years. Int. J. Climatol., 25, 279-294, https://doi.org/10.1002/ joc.1130.

— , G. J. Marshall, K. Clem, S. Colwell, T. Phillips, and H. Lu, 2020: Antarctic temperature variability and change from station data. Int. J. Climatol., 40, 2986-3007, https://doi.org/ 10.1002/joc. 6378 .

van Wessem, J. M., C. H. Reijmer, J. T. M. Lenaerts, W. J. van de Berg, M. R. van den Broeke, and E. van Meijgaard, 2014: Updated cloud physics in a regional atmospheric climate model improves the modelled surface energy balance of Antarctica. Cryosphere, 8, 125-135, https://doi.org/10.5194/tc8-125-2014.

Venema, V. K. C., and Coauthors, 2012: Benchmarking homogenization algorithms for monthly data. Climate Past, 8, 89-115, https://doi.org/10.5194/cp-8-89-2012.

Walters, D., and Coauthors, 2017: The Met Office Unified Model Global Atmosphere 6.0/6.1 and JULES Global Land 6.0/6.1 configurations. Geosci. Model Dev., 10, 1487-1520, https:// doi.org/10.5194/gmd-10-1487-2017.

Zentek, R., and G. Heinemann, 2020: Verification of the regional atmospheric model CCLM v5.0 with conventional data and lidar measurements in Antarctica. Geosci. Model Dev., 13, 1809-1825, https://doi.org/10.5194/gmd-131809-2020. 